\section{INDUSTRIAL CANCER OF THE BLADDER}

\section{Carcinogenic and Chronic Toxic Hazards of Aromatic Amines}

By T. S. Scott. (Elsevier Monographs on Toxic Agents.) Pp. $x i+208$. (Amsterdam and New York: Elsevier Publishing Company, Inc., 1962.) $30 s$.

THE development of the synthetic dye industry is a fascinating story full of romantic and also tragic events. As in many other passages of history, the full implications are not yet clear. As all the dyes are aromatic compounds, and so benzene derivatives, the story really began with the discovery of benzeno by Faraday in 1825. Twenty years later, Hofmann isolated benzene from coal-tar. The young W. H. Perkin, working in Hofmann's laboratory in London, obtained a mauve dye by oxidizing aniline in an attempt to synthesize quinine. Perkin sent a sample of this dye, which he called mauveine, to the dyer Sir Robert Pullar of Perth. As a result of this the manufacture of the dye on a commercial scale started, and Perkin took out a patent in 1856. The red dye, magenta or fuchsin, was discovered in France in 1859. During this period Griess developed the diazo reaction while working in a Burton brewery, and the Russian chemist Zinin discovered benzidine and 1-naphthylamine. Lieberman and Schneiding prepared 2-naphthylamine in 1879 .

During the past hundred years the synthetic dyostuffs industry, which is largely dependent on aromatic amines, has expanded enormously. At first the expansion was mainly in Germany and Switzerland, in spite of the fact that the first synthetic dye was discovered, manufactured and used in Britain. During the First World War, however, Britain, tho United States and other countries started their own dyestuffs industry because the German products were not available. The manufacture of synthetic dyestuffs is now carried on in many countries throughout the world. Many of the intermediates are also used in the manufacture of rubber products, paper, textiles, cables, pigments and plastics.

The first fifty years of the development of this side of the organic chemical industry were full of hope and success. Occasional toxic effects in workmen were seen, due to aniline and other amines causing methæmoglobinæmia and cyanosis. Sometimes the compounds caused irritation of the bladder, but provided that the working conditions were not exceptionally bad the effects were not considered serious.

In 1895, however, Rehn, a surgeon from Frankfurtam-Main, which was a centre of the dyestuffs industry, pointed out the incidence of bladder cancer in men employed in the industry. Rehn discussed the frequency of hrmaturia and cyanosis among the workers and considered that the bladder cancers seen in three men who had worked on the manufacture of magenta for periods varying from 15 to 29 years were due to exposure to anilino. He called the disease aniline cancer. It is now considered that aniline itself does not cause cancer, but the aniline used in the past century contained many other amines as impurities or contaminants. Magenta could not have been formed if the aniline used had been pure. As other countries took up tho manufacture of synthetic dyes the industrial bladder cancer appeared some decades after the commencement of manufacture.

As tho rosult of much long and careful investigation it was established that although aniline did not cause cancer, exposure to any of three aniline derivatives - 1-naphthylamine, 2-naphthylamine and benzidine-was associated with cancer of the bladder. Later it was shown that men exposed to xenylamine (4-aminobiphenyl) or the dyestuff 'Auramine' also developed the disease. The risk from 2-naphthylamine appeared to be greatest. The manufac- ture of 2-naphthylamine has ceased in most countries; this is due in part to the fact that many dyes can bo obtained without using the base itself. The other amines are now manufactured under improved conditions where the exposure to workers is minimal. There was, however, a delay of about half a contury between the first suggestion that aromatic amines could cause cancer in man and action to prevent the hazard.

The dolay was in part due to the difficulty in inducing cancer of the bladder in animals. The first species in which the carcinogenic aromatic amines induced bladder cancor was the dog. Hueper, working in the United States, produced bladder cancer by dosing dogs with 2-naphthylamine for two years. The evidence for the induction of exporimental bladder cancer with benzidine is less certain: but all the amines known to cause bladder cancer in man induce cancer at other sites in rodents.

As a result of the knowledge of the hazard from these compounds the exposure has been reduced. The Association of British Chemical Manufacturers invited a committee to draw up a "code of industrial practice to cover the manufacture and use of known or suspected bladder carcinogens". The code which was drawn up, mainly by Dr. T. S. Scott and the late Dr. Michael Williams, has been approved and widely adopted. Dr. Scott, who has himself played a major part in the development of the control of these dangerous compounds, has produced an interesting and authoritative account of the chemical, technical and medical aspects of the subject.

E. BOYLAND

\section{NUCLEAR ENERGY ON THE DESK}

Newnes Concise Encyclopaedia of Nuclear Energy Advisory Editors: D. E. Barnos, R. Batcholor, Dr. A. G. Maddock, J. A. Smedley and Dr. Denis Taylor. Pp. $x+886+8$ plates. (London: George Newnes, Ltd., 1962.) 160s. net.

7 HIS Encyclopaedia of Nuclear Energy has been produced "under the leadership and guidance of five Advisory Editors" all of whom are well known in their own fields. There is a foreword by Dr. H. Kronberger, but no oditorial introduction nor any indication of who bears the overall editorial responsibility - a pity, since the job seems to have been well done. It is necessary, therefore, to turn to the dust covor to learn that the book provides information on "theory, techniques and applications of nuclear science", is intended for "scientists, research workers, laboratory assistants and sixth form science students for A level", and that "over seventy scientists have contributed".

Nuclear energy is a wide topic; its applications involve some nuclear physics, engineering, biophysics, solidstate physics, metallurgy, and so on. Indeed its coverage might be expected to include somothing from most branches of science. This expectation is well realized and the topics treated do indeed give a fair picture of the scope of nuclear energy. It is no serious criticism to say that, occasionally, as in some of the biological articles, the bounds of nuclear energy appear to be exceeded but, even so, there are one or two gaps that merit filling in a second edition. For example, I could find no article on radiation damago, although there is one on the annealing of radiation damage. Nor is there anything about, neutron radiography or non-destructive testing.

There are many competent articles and some very good ones, for example, on atomic structure, atomic weapons and their effects, biological effects of radiation, reactors, nucloar fission, controlled thermonuclear research, to name a few. Some of the shorter definitions (for example, those of atomic interaction and neutron diffraction) are rather trivial, and one at least, that of cold neutrons, is incorrect. The covorage of the field of 